\title{
Fluid Flow in Tree-Shaped Constructal Networks: Porosity, Permeability and Inertial Parameter
}

\author{
Antonio F. Miguel \\ Department of Physics, University of Evora, Rua Romao Ramalho 59, 7000-671 Evora, Portugal \\ afm@uevora.pt
}

Keywords: tree flow networks, porous media, permeability, inertial parameter, constructal theory.

\begin{abstract}
This paper aims to contribute to the ongoing research on tree-shaped flow structures. First, it briefly traces the progress made on constructal tree-shaped flow networks. Then, the paper focuses on tree pattern of tubes connecting the centre and the rim of a circular area. It shows that the physical description underlying the classical Darcy-Forchheimer-Ergun equation may provide a legitimate correlation for this kind of flow structure. The porosity, hydraulic permeability and the inertial factor of the flow structure are also presented.
\end{abstract}

\section{Introduction}

Tree-shaped flow structures are ubiquitous in nature. From the geophysical to biological trees we can observe numerous structures that exhibit tree flow architectures [1-3]: river basins and deltas, the lungs, vascularised tissues of animal design, etc. The empirical view inherited to these is that tree-shaped flow structures are examples of spontaneous self-organization and self-optimization. This is why their features have been studied first in physiology and geophysics. Therefore, these flow structures are also prevalent in man-made flow systems both in macro and microfluidic devices [2]. A vast array of these systems is available and emerging in chemical engineering [4], electronics cooling [1], bioengineering [1,2], chemical and bioreactors [5], lab-on-a-chip systems [6], and smart materials with volumetric functionalities, such as self-healing and self-cooling [7]. Tree-shaped structures unite, in certain way, all the flow systems, the natural (animate or living, inanimate) and man-made systems.

In living organisms, the circulatory and respiratory systems consist of complex trees with millions of vessel segments having different diameters and lengths [1]. Although there is a great deal of heterogeneity in morphological (diameters and lengths) and hemodynamic (pressure, flow, etc.) parameters, the design of the vascular trees obeys to some simple principles that optimizes the operation of the system [3,4]. During the first half of the twentieth century, physiologists noticed that one basic feature of tree-shaped structures is that pairing, or bifurcation of tubes (dichotomy). Hess and Murray [1-3] analyzed the requirements in the distribution of blood vessel sizes of circulatory system, and concluded that the optimal ratio of tube diameters in a bifurcation $\left(\mathrm{D}_{0} / \mathrm{D}_{1}\right)$ is equal to $2^{1 / 3}$ (Hess-Murray law). This exponent (1/3) is invariant for all trees whose internal flows obey laminar conditions. For turbulent flow regime, the exponent was estimated to be equal to $1 / 2.33$ [8]. The specific geometry of the dichotomous branching also means that the tree-shaped flow distributes the wall shear stress uniformly throughout the flow space [9]. Other natural flow systems exhibit the same design. River basins (i.e., inanimate systems) are also trees, and they are united through correlations that are analogous to correlations in physiology [10].

For over a century now, researchers have been working on tree-shaped flow structures. Why this particular design is so important? How should large and small vessels be connected to one another? The purpose of a tree-shaped network is to make a flow connection between one point (source or sink) and an infinity of points (area or volume), or vice-versa. The constructal theory, articulated by Adrian Bejan [1-3], showed that these flow structures are the results of a process of optimization of global flow performance subject to constraints. Tree-shaped flow structures are so common in nature, both in animate and inanimate flow systems, because they are efficient (i.e., they are low resistive flow links inside the flow space). Geometry (configuration) is also the key to achieving 
maximum performance in engineering. Tree-shaped flow networks are often applied in man-made systems both in macro and microfluidic devices (see for example, [1-3]). Tree flow structures are so important in engineering because the relation among efficiency, complexity and compactness is essential to the progress toward design. In this direction, the compact and complex flow network becomes a designed complex flow structure (porous structure).

In the present work, we take a fresh look at fluid flow in tree-shaped patterns of tubes connecting the center and the rim of a circular area. This flow structure is viewed as a porous medium and the porosity, hydraulic permeability and inertial parameter are presented.

\section{Tree Pattern of Tubes for Fluid Flow in a Disc-Shaped Area}

Based on the constructal theory, Bejan and co-authors [1-3,10] theoretically investigated fluid flow in tree-shaped networks. These studies corroborated the observations of optimal ratio of tube diameters in a bifurcation reported by Hess, Murray and others [1,2,8], for both laminar and turbulent flows. Besides, they showed that pairing, or bifurcation of tubes (dichotomy), is the constructal design of providing best flow access. The best flow path (i.e., path of least flow resistance) that makes the connection of one point with infinity of points (line, area, or volume) is a structure bifurcating on several levels (i.e., tree-shaped flow network).
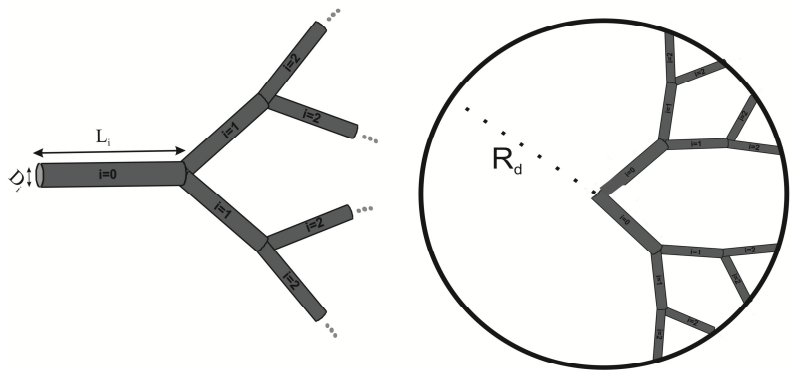

Fig. 1. Tree-shaped network $(\mathrm{N}=3 ; \mathrm{m}=2)$ and tree pattern of tubes connecting the centre and the rim of a circular area.

Consider tree-shaped paths of least flow resistance between the centre of a disc-shaped body of radius $R_{d}$ and points on its perimeter (Fig. 1). The tree-shaped path has $\mathrm{N}$ branches of tubes, from level 0 to level $\mathrm{n}$. Each tube branches into $\mathrm{m}$ daughter branches at the next level. The tubes are round tubes of several diameters $\left(\mathrm{D}_{\mathrm{i}}\right)$ and lengths $\left(\mathrm{L}_{\mathrm{i}} ; \mathrm{i}=0,1, \ldots\right)$. Bejan and co-authors [1-3] have shown that there is an optimal size step (diameter, length) at each pairing node such that the flow resistance is minimized (Hess-Murray law)

$\frac{D_{i+1}}{D_{i}}=a_{D} \quad \frac{L_{i+1}}{L_{i}}=a_{L}$

where $a_{D}$ and $a_{L}$ are scale factors independent of $i$. If the flow is laminar, the optimal geometric ratios of tube lengths and diameters change in the same proportion and the scale factors is $a_{D}=a_{L}=$ $2^{-1 / 3}[1,3]$. If the flow is turbulent, the optimal scale factors $a_{D}$ and $a_{L}$ are $2^{-3 / 7}$ and $2^{-1 / 7}$, respectively [3]. The relationship between the size of the first tube (level 0 ) and the size of the tubes at level $\mathrm{i}$ is given by

$\frac{\mathrm{D}_{\mathrm{i}}}{\mathrm{D}_{0}}=\mathrm{a}_{\mathrm{D}}{ }^{\mathrm{i}} \quad \frac{\mathrm{L}_{\mathrm{i}}}{\mathrm{L}_{0}}=\mathrm{a}_{\mathrm{L}}{ }^{\mathrm{i}}$ 
Consider that there are $\omega$ identical tree-shaped pattern of tubes connecting the centre and the rim of a circular area (Fig. 1). The effective length of each tree path, L, is

$$
\mathrm{L}=\sum_{\mathrm{i}=0}^{\mathrm{n}} \mathrm{L}_{\mathrm{i}}
$$

and the total side area, A, and volume, V, are, respectively

$$
A=\sum_{i=0}^{n} 4 m^{i} \alpha_{s f} D_{i} L_{i} \quad V=\sum_{i=0}^{n} m^{i} \alpha_{s f} D_{i}^{2} L_{i}
$$

where $\mathrm{m}$ is the number of branches of each tree pattern of tubes, $\mathrm{n}$ is the final branching level of each pattern, and $\alpha_{\mathrm{sf}}$ is a shape factor (i.e., $\pi / 4$ ). One basic feature of tree-shaped flow networks is that bifurcation of tubes (dichotomy), is an optimized feature of the flow architecture [1-3]. Therefore, m should take a value of 2. Substituting Eq. (2) into Eqs. (3) and (4) we obtain

$$
\mathrm{L}=\mathrm{L}_{0} \frac{1-\mathrm{a}_{\mathrm{L}}^{\mathrm{n}+1}}{1-\mathrm{a}_{\mathrm{L}}} \quad \mathrm{A}=\alpha_{\mathrm{sf}} \mathrm{D}_{0} \mathrm{~L}_{0} \frac{1-\left(m a_{D} \mathrm{a}_{\mathrm{L}}\right)^{\mathrm{n}+1}}{1-m a_{\mathrm{D}} \mathrm{a}_{\mathrm{L}}} \quad \mathrm{V}=\alpha_{\mathrm{sf}} \mathrm{D}_{0}^{2} \mathrm{~L}_{0} \frac{1-\left(m \mathrm{a}_{\mathrm{D}}^{2} \mathrm{a}_{\mathrm{L}}\right)^{\mathrm{n}+1}}{1-m \mathrm{a}_{\mathrm{D}}^{2} \mathrm{a}_{\mathrm{L}}}
$$

An important structural parameter of the tree pattern of tubes in the disc-shaped area is the porosity. The porosity or void fraction, $\varepsilon$, is defined as the ratio between the void area and the disc-shaped area

$$
\varepsilon=\omega \frac{4 \mathrm{D}_{0} \mathrm{~L}_{0} 1-\left(m a_{D} a_{L}\right)^{n+1}}{R_{d}^{2}} \frac{m a_{D} a_{L}}{1-{ }_{1}}
$$

Equation (6) shows the porosity of the tree pattern of tubes in the disc-shaped area in terms of the size of the first tube, number of branches, branching level and diameter of disc-shaped body.

\section{Fluid flow through tree-shaped networks}

Consider that the flow is fully developed, and inlet and exit effects are neglected. The steady-state fluid velocity through a tube can be related to the pressure difference as

$\rho v\left(\frac{\lambda R e}{2}\right)\left(\frac{L}{D^{2} \mathrm{~A}}\right) \mathrm{Q}=\Delta \mathrm{p}$

Here $Q$ is the fluid flow, $\rho$ is the fluid density, $v$ is the kinematic fluid viscosity, $\lambda$ is the friction factor, $\Delta \mathrm{p}$ is the pressure difference and Re is the Reynolds number $\left(=\frac{\mathrm{QD}}{v \mathrm{~A}}=\frac{\mathrm{Q}}{\alpha_{\mathrm{sf}} v \mathrm{D}}\right)$. For Newtonian fluids in smooth tubes, the friction factor is a unique function of the Reynolds number which for Re $\leq 2300$ (Hagen-Poiseuille flow) is $\lambda=64 / \mathrm{Re}$, and for Reynolds numbers from 2300 up to $10^{5}$ is well approximated by $\lambda=8 \operatorname{Re}^{2}\left\{\left[\ln (\operatorname{Re} / 7)^{2.21 \operatorname{Re}}\right]^{16}+(37530)^{16}\right\}^{-1 / 8}$. Therefore, substituting these equations into Eq. (7) yields

$$
\begin{aligned}
& 32 \rho v\left(\frac{\mathrm{L}}{\mathrm{D}^{2} \mathrm{~A}}\right) \mathrm{Q}=\Delta \mathrm{p} \quad \text { for } \mathrm{Re} \leq 2300 \\
& 4 \rho \operatorname{Re}^{2}\left\{\left[\ln \left(\frac{\mathrm{Re}}{7}\right)^{2.21 \mathrm{Re}}\right]^{16}+(37530)^{16}\right\}^{-1 / 8}\left(\frac{\mathrm{L}}{\mathrm{DA}^{2}}\right) \mathrm{Q}^{2}=\Delta \mathrm{p} \quad \text { for } 2300<\mathrm{Re}<10^{5}
\end{aligned}
$$

We now turn our attention to tree-shaped networks. According to the mass conservation, the fluid flow is a constant in every level of the tree network. Therefore, 
$\Delta \mathrm{p}=\sum_{\mathrm{i}=0}^{\mathrm{n}} \Delta \mathrm{p}_{\mathrm{i}}$

Substituting Eqs. (5), (8) and (9) into (10), we obtain

$$
\begin{aligned}
& \Delta p=32 \rho v Q \sum_{i=0}^{n}\left(\frac{L}{D^{2} A}\right)_{i}=32 \frac{\rho v L_{0}}{\alpha_{s f} D_{0}^{4}} \frac{1-\left(a_{L} / m a_{D}^{4}\right)^{n+1}}{1-\left(a_{L} / m a_{D}^{4}\right)} Q \quad \text { for } R e \leq 2300 \\
& \Delta p=4 \frac{\rho \operatorname{Re}^{2} L_{0}}{\alpha_{s f}^{2} D_{0}^{5}}\left\{\left[\ln \left(\frac{\operatorname{Re}}{7}\right)^{2.21 R e}\right]^{16}+(37530)^{16}\right\}^{-1 / 8} \frac{1-\left(a_{L} / m_{D}^{5}\right)^{n+1}}{\left(1-a_{L} / m a^{5}\right)} Q^{2} \quad \text { for } 2300<R e<10^{5}
\end{aligned}
$$

Consider that there are $\omega$ tree-shaped pattern of tubes connecting the centre and the rim of a circular area (Fig. 1). The pressure difference is given by

$$
\begin{aligned}
& \Delta \mathrm{P}=32 \frac{\rho v \mathrm{~L}_{0}}{\alpha_{\mathrm{sf}} \omega \mathrm{D}_{0}^{4}} \frac{1-\left(\mathrm{a}_{\mathrm{L}} / \mathrm{ma}_{\mathrm{D}}^{4}\right)^{\mathrm{n}+1}}{1-\mathrm{a}_{\mathrm{L}} / \mathrm{ma}_{\mathrm{D}}^{4}} \mathrm{Q} \quad \text { for } \mathrm{Re} \leq 2300 \\
& \Delta \mathrm{P}=4 \frac{\rho \mathrm{Re}^{2} \mathrm{~L}_{0}}{\omega \alpha_{\mathrm{sf}}^{2} \mathrm{D}_{0}^{5}}\left\{\left[\ln \left(\frac{\mathrm{Re}}{7}\right)^{2.21 \mathrm{Re}}\right]^{16}+(37530)^{16}\right\}^{-1 / 8} \frac{1-\left(\mathrm{a}_{\mathrm{L}} / \mathrm{ma}_{\mathrm{D}}^{5}\right)^{\mathrm{n}+1}}{\left(1-\mathrm{a}_{\mathrm{L}} / \mathrm{maD}^{5}\right)} \mathrm{Q}^{2} \quad \text { for } 2300<\mathrm{Re}<10^{5}
\end{aligned}
$$

where $\Delta \mathrm{P}$ is the pressure difference between the centre and the rim of a circular area.

\section{Hydraulic permeability and inertial parameter of tree pattern of tubes in a disc-shaped body}

A porous material is a solid structure with several interconnected pores, tubes or channels. Consequently, tree pattern of tubes in a disc-shaped body may be viewed as a porous material.

A standard approach in the investigation of fluid flow through porous materials is to characterize the system in terms of Darcy's law. Darcy's law, just as the Hagen-Poiseuille equation, is valid at small values of the Reynolds number and establishes a linear relation between the pressure difference and the fluid flow with the proportional coefficient depending on the hydraulic permeability (transport property for flow) and fluid viscosity. Several authors [2] pointed out the limitations of Darcy's law in describing flows accompanied by boundary and inertial effects. In spite of its great applicability, the concept of permeability as a global transport property for flow is restricted to viscous flow conditions. Unlike the transition from laminar to turbulent flow in pipes and channels, there is also a critical Reynolds number value separating the passage from a linear (Darcy's law) to nonlinear behaviour in porous materials. The classical approach that accounts for both effects on fluid flow is the Darcy-Forchheimer-Ergun equation, $\frac{\rho v}{K A} Q+\rho \frac{c_{\text {ine }}}{A^{2}} Q^{2}=\frac{\Delta P}{R_{d}}$, where $R_{d}$ is the radius of the disc-shaped body, $\mathrm{K}$ is hydraulic permeability of the porous material and $\mathrm{c}_{\text {ine }}$ is usually called the "inertial parameter". Both $\mathrm{K}$ and $\mathrm{c}_{\text {ine }}$ should depend on the porosity $\varepsilon$ of the porous material. In summary, the linear term accounts for the contribution of viscous forces and nonlinear can be interpreted as a second order correction to account for the contribution of inertial forces in fluid flow.

Combining Darcy-Forchheimer-Ergun with Eqs. (13) and (14), we find that the permeability and the inertial factor are given by

$$
\begin{aligned}
& \mathrm{K}=\frac{\varepsilon 1-\left(m a_{D} a_{L}\right)}{1281-\left(m a_{D} a_{L}\right)^{n+1}} \frac{\left(1-a_{L} / m a_{D}^{4}\right)}{1-\left(a_{L} / m a_{D}^{4}\right)^{n+1}} \frac{R_{d}^{3} D_{0}}{L_{0}^{2}} \\
& c_{\text {ine }}=\frac{16 \operatorname{Re}^{2}}{\varepsilon}\left\{\left[\ln (\operatorname{Re} / 7)^{2.21 R e}\right]^{16}+(37530)^{16}\right\}^{-1 / 8} \frac{1-\left(a_{L} / m a_{D}^{5}\right)^{n+1}}{\left(1-a_{L} / m a^{5}\right)} \frac{1-\left(m a_{D} a_{L}\right)^{n+1}}{1-m a_{D} a_{L}} \frac{L_{0}^{2}}{R_{d}^{3}}
\end{aligned}
$$


Eq. (15) shows that the permeability of the tree pattern of tubes in a disc-shaped body is only a function of the geometry and size of both the tree patterns of tubes and disc-shaped body. The inertial parameter (Eq. 16) is dependent not only on geometry and size of both the tree patterns of tubes and disc-shaped body, but also on the Reynolds number.

Eqs. (15) and (16) show that physical description underlying the classical Darcy-ForchheimerErgun equation offers a legitimate description of fluid flow through a tree pattern of tubes in a discshaped body over a wide range of Reynolds number conditions. It is interesting to study the influence of some quantities on $\mathrm{K}$ and $\mathrm{c}_{\text {ine }}$. Consider that $\mathrm{a}_{\mathrm{D}}, \mathrm{a}_{\mathrm{L}}$ and $\mathrm{m}$ are constants. Then, by taking the logarithm on both sides of the Eq. (15) and differentiating, yields

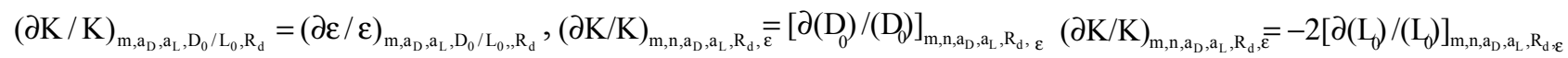
$(\partial \mathrm{K} / \mathrm{K})_{\mathrm{m}, \mathrm{n}, \mathrm{a}_{\mathrm{D}}, \mathrm{a}_{\mathrm{L}}, \mathrm{D}_{0} / \mathrm{L}_{0}, \varepsilon}=3\left(\partial \mathrm{R}_{\mathrm{d}} / \mathrm{R}_{\mathrm{d}}\right)_{\mathrm{m}, \mathrm{n}, \mathrm{a}_{\mathrm{D}}, \mathrm{a}_{\mathrm{L}}, \mathrm{D}_{0} / \mathrm{L}_{0}, \varepsilon}$. These results show that the permeability varies proportionally to porosity and $\mathrm{D}_{0}$. When $\mathrm{L}_{0}$ or $\mathrm{R}_{\mathrm{d}}$ increases, the permeability varies 2 or 3 times faster. Besides, the impact of the final branching level of each pattern, $\mathrm{n}$, on the hydraulic permeability depends on structural parameters $\mathrm{a}_{\mathrm{D}}, \mathrm{a}_{\mathrm{L}}$ and $\mathrm{m}$.

According to Eq. (16) taking the logarithm on both sides of the each equation and differentiating, yields

$\left(\partial \mathrm{c}_{\mathrm{ine}} / \mathrm{c}_{\mathrm{ine}}\right)_{\mathrm{m}, \mathrm{n,a}, \mathrm{a}_{\mathrm{t}}, \mathrm{R}, \mathrm{Re}, \mathrm{R}_{\mathrm{d}}, \varepsilon}=2\left[\partial\left(\mathrm{L}_{0} / \mathrm{L}_{0}\right)\right]_{\mathrm{m}, \mathrm{n}, \mathrm{a}_{\mathrm{D}}, \mathrm{a}_{\mathrm{L}}, \mathrm{Re}, \mathrm{R}_{\mathrm{d}}, \varepsilon}$

, $\left(\partial \mathrm{c}_{\text {ine }} / \mathrm{c}_{\text {ine }}\right)_{\mathrm{m}, \mathrm{n}, \mathrm{a}_{\mathrm{a}}, \mathrm{a}_{\mathrm{L}}, \mathrm{Re}_{\mathrm{R}} \mathrm{R}_{\mathrm{d}}, \mathrm{D}_{0} / \mathrm{L}_{0}}=-(\partial \varepsilon / \varepsilon)_{\mathrm{m}, \mathrm{n}, \mathrm{a}_{\mathrm{p}}, \mathrm{a}_{\mathrm{L}}, \mathrm{Re}_{\mathrm{e}}, \mathrm{R}_{\mathrm{d}}, \mathrm{L}_{0}}$ and

$\left(\partial c_{\text {ine }} / c_{\text {ine }}\right)_{m, n, a_{0}, a_{L}, L_{0}, R e}=-3\left(\partial R_{d} / R_{d}\right)_{m, n, a_{0}, a_{L} L_{0}, R e} \quad$. Notice that $c_{\text {ine }}$ becomes lower at higher $\varepsilon$ and $R_{d}$.

Besides, when $\mathrm{L}_{0}$ increases the inertial parameter decreases two times faster.

\section{Concluding remarks}

This paper is devoted to tree-shaped flow networks. Based on the insight gained on existing experimental and constructal studies, an approach is presented combining the hydrodynamics with the geometric description of the tree network. This formulation is applied to a tree pattern of tubes in a disc-shaped body. We show that the physical description underlying the classical DarcyForchheimer-Ergun equation provides a legitimate correlation for these configurations, and the hydraulic permeability and the inertial factor of the flow structure are presented.

\section{References}

[1] A. Bejan, Shape and Structure, from Engineering to Nature (Cambridge University Press, Cambridge, 2000)

[2] A. Bejan, I. Dincer, S. Lorente, A. F. Miguel and A. H. Reis, Porous and Complex Flow Structures in Modern Technologies (Springer, 2004)

[3] A. Bejan and S. Lorente, Design with Constructal Theory (Wiley, New Jersey, 2008)

[4] D. Tondeur, L. Luo and D. D'Ortona: Entropie Vol. 30 (2000), p. 32.

[5] M. Kearney: Chem. Eng. Commun. Vol. 173 (1999), p. 43.

[6] D. R. Emerson, K. Cieslicki, X. Gu and R. Barber: Lab on a Chip Vol. 6 (2006), p. 447.

[7] J. Lee, S. Kim, S. Lorente and A. Bejan: Int. J. Heat Mass Trans. Vol. 51(2008), p. 2029.

[8] G. S. Kassab: Am. J. Physiol. Heart Circ. Physiol. Vol. 290 (2006), p. 894.

[9] P. V. Stroev, P. Hoskins and W. Easson: Atherosclerosis Vol. 191 (2007), p. 276.

[10] A. Bejan and J. H. Marden: Physics of Life Reviews Vol. 6 (2009), p. 85. 
Fluid Flow in Tree-Shaped Constructal Networks: Porosity, Permeability and Inertial Parameter

doi:10.4028/www.scientific.net/DDF.297-301.408

\section{References}

[1] A. Bejan, Shape and Structure, from Engineering to Nature (Cambridge University Press, Cambridge, 2000)

[2] A. Bejan, I. Dincer, S. Lorente, A. F. Miguel and A. H. Reis, Porous and Complex Flow Structures in Modern Technologies (Springer, 2004)

[3] A. Bejan and S. Lorente, Design with Constructal Theory (Wiley, New Jersey, 2008) doi:10.1002/9780470432709

[4] D. Tondeur, L. Luo and D. D'Ortona: Entropie Vol. 30 (2000), p. 32.

[5] M. Kearney: Chem. Eng. Commun. Vol. 173 (1999), p. 43.

doi:10.1080/00986449908912775

[6] D. R. Emerson, K. Cieslicki, X. Gu and R. Barber: Lab on a Chip Vol. 6 (2006), p. 447. doi:10.1039/b516975e

PMid: 16511629

[7] J. Lee, S. Kim, S. Lorente and A. Bejan: Int. J. Heat Mass Trans. Vol. 51(2008), p. 2029. doi:10.1016/j.ijheatmasstransfer.2007.06.015

[8] G. S. Kassab: Am. J. Physiol. Heart Circ. Physiol. Vol. 290 (2006), p. 894. doi:10.1152/ajpheart.00579.2005

PMid:16143652

[9] P. V. Stroev, P. Hoskins and W. Easson: Atherosclerosis Vol. 191 (2007), p. 276. doi:10.1016/j.atherosclerosis.2006.05.029

PMid:16828101

[10] A. Bejan and J. H. Marden: Physics of Life Reviews Vol. 6 (2009), p. 85. doi:10.1016/j.plrev.2008.12.002 